\title{
Sara FumAgalli: Wege zu einer neuen \\ Phänomenologie: Landgrebe, Fink und Patocka im \\ Dialog, Würzburg, Ergon-Verlag. Studien zur \\ Phänomenologie und praktischen Philosophie, 2017, \\ 151 pp.
}

\author{
Noé Expósito \\ UNED \\ nexposito@fsof.uned.es
}

La obra que reseñamos es el primer libro publicado de la profesora Sara Fumagalli, Wege zu einer neuen Phänomenologie: Landgrebe, Fink und Patocka im Dialog. Como va indicado en el título mismo, el objetivo principal de Fumagalli es mostrarnos otros caminos hacia una nueva fenomenología, sirviéndose para ello de tres autores clásicos ya de la tradición fenomenológica: Ludwig Landgrebe (Viena, 1902 - Colonia, 1991), Eugen Fink (Constanza, 1905 - Friburgo de Brisgovia, 1975) y Jan Patočka (Turnov, 1907 - Praga, 1977). Aunque son de sobra conocidas, remarco desde el comienzo tanto el lugar como las fechas de estas biografías porque este será, precisamente, el hilo conductor adoptado por Fumagalli para reconstruir la relación entre estos tres autores: la dimensión biográfica. Tal y como nos muestra la autora apoyándose en la correspondencia epistolar, alguna de ella inédita, como la mantenida entre Landgrebe y Patočka durante más de tres décadas (1940-1976), la relación entre estos tres fenomenólogos alcanzó el rango de verdadera amistad personal. Tal es, efectivamente, una de las grandes novedades que nos ofrece esta obra, pues, insisto, estamos ante materiales inéditos - conservados en el Archivo Patočka de Praga- que nos 
muestran fehacientemente la estrecha relación personal entre estos tres discípulos, cada uno a su modo, de Edmund Husserl y Martin Heidegger. Así, tras dedicar un primer capítulo introductorio al "Contexto histórico del diálogo" (pp. 13-29), apoyándose, entre otras, en la famosa obra de Hannah Arendt sobre Los orígenes del totalitarismo, lo cual nos muestra desde el principio la actitud crítica -en el mejor sentido del término- adoptada por la autora, y no meramente descriptiva, nos ofrece en el segundo capítulo (pp. 31-62) un análisis detallado de la citada correspondencia entre los tres fenomenólogos. $\mathrm{O}$, dicho con más precisión, de la correspondencia, por un lado, entre Fink y Patočka (pp. 31-46) y, por otro, entre Landgrebe y Patočka (pp. 46-62). Ahora bien, más allá del estudio de las relaciones biográficas, que en el caso de Fink y Patočka queda igualmente atestiguada por el intercambio epistolar mantenido durante más de cuatro décadas, entre 1933 y 1977, el estudio de Fumagalli es de carácter estrictamente filosófico. Tal y como como nos indica desde el comienzo, la autora insiste en que el valor de estos materiales reside, precisamente, en mostrarnos cómo en el diálogo informal y espontáneo se refleja, en primer lugar, la convicción compartida por estos tres autores de que la fenomenología, tanto en su versión husserliana como heideggeriana, ya no era suficiente, nicht mehr genügt (cfr. p. 7). Ahora bien, esta primera aproximación -crítica o deconstructiva, pars destruens, en palabras de la autora (cf. p. 10)—, nos remitiría, en un segundo momento, al proyecto, también compartido por estos tres autores, de "una innovativa recuperación de la metafísica, justamente, una fenomenología metafísica" (cfr. p. 12). Tal es, efectivamente, el objetivo último de Fumagalli, mostrar cómo en el intercambio epistolar se van fraguando, en diálogo crítico, las tres propuestas filosóficas de nuestros autores. Esta tarea será la que nuestra autora emprenderá ya decididamente en el tercer capítulo de la obra, titulado "La fenomenología en diálogo: los nuevos caminos que se muestran en el intercambio epistolar" (pp. 63-144). Este queda dividido, a su vez, en tres extensos epígrafes, uno dedicado a "Ludwig Landgrebe y el «método del Leitfäden»" (pp. 66-100), otro a "Eugen Fink: fenomenología de la fenomenología" ( pp. 100-122), y un último a "Jan Patočka y la fenomenología asubjetiva" (pp. 122-137). Es, pues, en este tercer capítulo donde la autora recoge y sintetiza las líneas directrices expuestas en el capítulo precedente, dedicado al intercambio epistolar, para esbozar su propia lectura de estos tres autores y, a partir de ella, "una nueva fenomenología metafísica", tal y como queda reflejado en el título mismo de la “Conclusión” (pp. 139-144). Con esto 
queda trazado ya el marco general de la obra, tanto su punto de partida como de llegada.

No es mi objetivo aquí, puesto que excede los límites de una reseña, detenerme en los interesantes y complejos temas que Fumagalli va abordando a lo largo de la obra, sino invitar al lector a que emprenda por sí mismo una lectura que, me atrevería a decir, resultará fructífera y reveladora incluso a los estudiosos más versados en la tradición fenomenológica, y no solo por los materiales inéditos ofrecidos, sino también, y sobre todo, por la originalidad de algunos de los planteamientos esbozados por la autora al hilo del diálogo filosófico entre estos tres fenomenólogos. En un estilo claro, sistemático y ameno -recordemos que el estudio no excede las ciento cincuenta páginas-, la autora logra sintetizar los puntos realmente relevantes en este diálogo, tanto en su dimensión crítica ( sin eludir la problemática confrontación con los maestros), como constructiva o propositiva. Respecto a lo primero, si bien es cierto que la autora se limita a exponer, y no a problematizar, algunas de las críticas que los discípulos - sobre todo Patočka- formularon al fundador de la fenomenología, tales como el supuesto solipsismo inherente a la epojé husserliana (cfr. pp. 126; 132-133), la recaída en el idealismo tradicional (cfr. pp. 135-137), o incluso la asunción de que la fenomenología de Husserl no atendió —ni entendió- realmente la historia (cfr. p. 139), prejuicios todos ellos más que superados en la bibliografía husserliana que hoy conocemos, lo cierto es que la contraposición entre las propuestas específicas de los tres discípulos y las de los maestros ayuda a enfatizar la originalidad y especificidad de las mismas. Respecto a lo segundo, es de destacar, como ya he indicado, el rigor expositivo de Fumagalli a la hora de adentrarse en los escritos de los tres fenomenólogos, sin esquivar ninguno de los complejos problemas en juego. Y esto, además, sin perder de vista el objetivo principal de su estudio, que no es ofrecer un análisis aislado de los distintos autores, sino, justamente, de sus afinidades y discrepancias. Así, por ejemplo, en el epígrafe dedicado a Landgrebe, la autora nos muestra el hilo conductor que recorre toda su obra, desde su primerizo estudio Der Begriff des Erlebens (1929-1932) publicado póstumamente, como es sabido, en 2010 - hasta su último libro, Faktizität und Individuation (1982), caracterizada por Fumagalli como "una ontología del ser humano" o "antropología a priori" (cfr. p. 67). En el marco de esta lectura general de la obra de Landgrebe, la autora analiza también el papel de las sensaciones, la afectividad o la corporalidad en los textos del filósofo austriaco (cfr. 
pp. 89-91), sin que ello le impida, insisto, desatender su objetivo principal, que es destacar la dimensión metafísica a la que nos conducirían las propuestas de los tres amigos fenomenólogos en su abordaje de los problemas clásicos de la fenomenología, tales como el de la reducción fenomenológica, que nos conduciría, entre otros, al problema de "la apertura del mundo" o al de una "experiencia originaria" (cfr. pp. 97-99). Tales cuestiones son, como es sabido, las que Landgrebe aborda explícitamente en escritos como "Phänomenologie und Metaphysik" (1949), pero no serán otras las que empujen a Fink a desarrollar una "fenomenología constructiva", cuyas dos primeras tareas principales serían, tal y como explica Fumagalli, confrontar los problemas relacionados, por un lado, con la "totalidad egológica” y, por otro, con la "intersubjetividad" (cfr. p. 106). Esto quiere decir que, en última instancia, la "fenomenología de la fenomenología" esbozada por Fink no se limita a la problemática metodológica, a Die I dee einer transzendentalen Methodenlehre, para decirlo con el ensayo de 1932, sino que todas estas cuestiones, como la referida a la "ausencia de motivación de la reducción" ( Motivationslosigkeit» der Reduktion), nos remiten, como explica Fumagalli, no ya al "sujeto" de la reflexión fenomenológica, sino "al lugar desde el cual la cosa aparece al sujeto", rehabilitando, así, la problemática de "la aparición del mundo" (cfr. p. 117). Partiendo de esta temática general, y sin desatender los trabajos de algunos de los estudiosos más destacados sobre esta materia, como los de Hans Rainer Sepp o Ronald Bruzina (cfr. pp. 118-119), la autora logra trazar con toda claridad el camino que conecta los textos de estos dos discípulos de Husserl con los de Jan Patočka y su propuesta de una "fenomenología asubjetiva". Como explica Fumagalli, para el filósofo checo la fenomenología no tendrá como objetivo principal el estudio de la subjetividad, sino "del ser mismo", esto es, "el aparecer mismo" (cfr. p. 123). Así, el proyecto de Patočka, partiendo de la propia fenomenología de Husserl y su concepto de "mundo de la vida" (Lebenswelt), apuntaría, explica nuestra autora, hacia una "historia de la ontología de la subjetividad" en relación, siempre, "con la libertad humana" (cfr. 124). Se trata, por tanto, al igual que en Fink y Landgrebe, de la pregunta por la "constitución intersubjetiva del mundo", problematizando ahora la conocida idea heideggeriana expuesta en Ser y tiempo según la cual estamos "arrojados" (geworfen) al mundo, sin reparar, matizará Patočka, en que toda "venida al mundo" (zur Welt kommen) tiene como condición previa una "aceptación", un ser "acogido" (angenommen) por el otro (cfr. p. 126). Así, como señala Fumagalli, podría 
considerarse que el pensamiento de Patočka representa "una perfecta síntesis entre la intencionalidad husserliana como punto de partida y el análisis heideggeriano del tiempo como desarrollo del estudio de los fenómenos" (p. 124). Junto a estos conceptos destaca la autora la importancia en Patočka de la pregunta por "la identidad de Europa" (cfr. ib.) tal y como fue planteada por Husserl en La crisis de las ciencias europeas (1936), problemática que, como hoy sabemos, se retrotrae, al menos, a comienzo de los años veinte, tal y como atestiguan, por ejemplo, los artículos de Kaizo (1923-1924) o su ensayo sobre “La idea de una cultura filosófica" (1923). De igual importancia resultará para el filósofo checo el concepto husserliano de "mundo natural" (natürliche Welt), a partir del cual, señala Fumagalli, desarrollará Patočka su conocida teoría sobre "el movimiento de la existencia humana" (cfr. p. 125), perfectamente sintetizada como sigue: "A la tríada de los movimientos de la existencia humana, piedra angular del pensamiento de Patočka, corresponde así una trinidad de categorías fenomenológicas intrínsecamente conectadas: la corporalidad se conecta con el primer movimiento de enraizamiento; la temporalidad con el segundo de reproducción; y la intersubjetividad con el tercero de apertura" (p. 128). Por ello, como concluye Fumagalli, el proyecto de Patočka puede concebirse como "una fenomenología de la existencia que coincide con una cosmología fenomenológica", el cual nos remite, a su vez, al proyecto cosmológico de Eugen Fink (cfr. p. 132). Así, una vez más, sería el concepto de "mundo", tomado ya desde su aparecer mismo, y no desde la subjetividad, el que nos abriría el camino hacia una nueva fenomenología metafísica, hacia la problemática cosmológica como rasgo característico fundamental de las propuestas de estos tres fenomenólogos, tal y como concluye Fumagalli en las páginas finales del libro que presentamos: “A diferencia de Husserl, tanto Landgrebe como Fink y Patočka sostienen que el objeto por excelencia del preguntar fenomenológico no sería el sujeto, sino el origen del mundo" (p. 139). Esta tesis quedaría claramente sintetizada en una carta de Patočka a Fink, en la que se sostiene taxativamente que la fenomenología, en tanto que "doctrina del aparecer" (Erscheinungslehre), no se dirige a la subjetividad, sino al ser (cfr. ib.), de ahí su proyecto de una "fenomenología asubjetiva". Cabría preguntarnos, sin embargo, si esta tesis sería igualmente formulada - y aceptada - tanto por Fink como por Landgrebe. Recordemos, por ejemplo, y sin ir más lejos, que la propia Fumagalli nos presenta el proyecto filosófico de Landgrebe como "una ontología del ser humano" o "antropología a priori" (cfr. p. 67), lo cual parece 
prácticamente inconcebible al margen de una filosofía que, como diría José Ortega y Gasset recurriendo a la lengua materna de nuestra autora, mande a la subjetividad al lazzaretto; y no digamos ya en una fenomenología "asubjetiva", como la propuesta por Jan Patočka, por más que esta se nos presente, por otro lado, en el marco de una "historia de la ontología de la subjetividad" y asuma como problemática central "la libertad humana", tal y como destacaba la propia autora (cfr. 124). Tales cuestiones exceden con mucho los límites de una reseña, limitada siempre, en el mejor de los casos, a un esbozo más o menos certero de las líneas generalísimas de la obra presentada, cuyo estudio pormenorizado no puede quedar aquí más que sugerido al ávido lector. Merece la pena, a mi juicio, llevar a cabo una traducción española de esta obra para facilitar al lector hispanohablante un acceso claro, conciso y riguroso a las propuestas filosóficas de Ludwig Landgrebe, Eugen Fink y Jan Patočka, discípulos prominentes, cada uno a su modo, de Edmund Husserl y Martin Heidegger —en fecunda y compleja conjunción de ambos maestros, como bien nos muestra Sara Fumagalli. 